\title{
KNOWLEDGE, ATTITUDE AND PERCEPTION OF CONTRACEPTION AMONG MEDICAL STUDENTS IN UNIVERSITI PUTRA MALAYSIA
}

\author{
Ma Saung $00^{1 *}$, Nursyahira Binti Mohd Ismail ${ }^{2}$, Wei Rou Ean ${ }^{3}$, Habibah Abdul Hamid ${ }^{4}$ and Nik Rafiza \\ Affendi $^{5}$ \\ ${ }^{1}$ Department of Obstetrics and Gynaecology, Faculty of Medicine and Health Sciences, Universiti Sultan Zainal Abidin \\ ${ }^{2}$ Second Year Medical Student, Faculty of Medicine and Health Sciences, University Putra Malaysia \\ ${ }^{3}$ Second Year Medical Student, Faculty of Medicine and Health Sciences, University Putra Malaysia \\ ${ }^{4}$ Department of Obstetrics and Gynaecology, Faculty of Medicine and Health Science, Universiti Putra Malaysia \\ ${ }^{5}$ Department of Obstetrics and Gynaecology, Faculty of Medicine and Health Sciences, Universiti Sains Malaysia
}

Corresponding author: Ma Saung Oo

Email: saung2012yh@yahoo.com,OR masaung@unisza.edu.my

\begin{abstract}
The incidence of unintended pregnancy and unsafe abortion are significantly high due to the lack of knowledge and negative attitude towards contraception and it can be prevented by effective and appropriate contraceptive knowledge and usage. Considering the future role of medical students as family planning educator as well as counsellors, it is not only important to determine their knowledge, attitude and perception towards contraception but also should be updated for improvement on the quality of future healthcare professionals on contraceptive knowledge which may lead to the reduction in the number of unintended pregnancy with improving maternal morbidity and mortality. This was a cross sectional study using self-reported questionnaires survey that consists of four sections as socio-demographic characteristics information, knowledge towards contraception, attitude towards contraception, and perception of education and training in sexual and reproductive health among medical student. Questions were, distributed among medical students in Faculty of Medicine and Health Sciences and analyzed. The response rate was 100\%. and most of the respondents in this study were Malay (64.4\%), female (68.3\%), single (98.6\%) and live in urban area (69.1\%). Most of their parents had tertiary education level (father educational level, 63.3\%; mother educational level, 50.0\%). 56. $1 \%$ of the respondents had poor level of knowledge and $59.2 \%$ of them had negative attitude towards contraception. Regarding the perception on contraception, most of the respondents thought that they did not have sufficient clinical practice (50.4\%) though adequate training (57.6\%) in counselling the patients for family planning service during their clinical posting. There was a significant association between gender, place of birth, ethnicity, marital status, father educational status and level of knowledge. There were a higher percentage of respondents who had poor knowledge and negative attitude towards contraception. Assessing the knowledge and attitude of medical students on contraception and their relationship with socio-demographic characteristics and socio-economic factors plays a leading role in public health projects which are aimed to combat maternal mortality through reducing unintended pregnancies. To change the attitude towards contraception and further increase the level of knowledge of contraception among medical students, collaborated health education and similar studies among health workers are highly recommended.
\end{abstract}

Keywords: Contraception, Family planning, Medical students, Knowledge, Attitude, Perception, Unintended pregnancy.

\section{INTRODUCTION}

Every year, about 42 million women with unintended pregnancies choose abortion and almost half of these procedures are taken place unsafe worldwide. ${ }^{1}$ These made a significant contribution to the global burden of maternal mortality and morbidity. ${ }^{1}$ Among those women who underwent unsafe abortion, 68,000 women die annually, making it one of the leading causes of maternal mortality (13\%). ${ }^{2}$ Whereas in Malaysia, there will be 17 abortions in every 1000 of life birth. ${ }^{3}$ Contraceptive practice is effective in reducing unintended pregnancy and maternal mortality in developing countries. It is estimated that by the use of effective contraception, $90 \%$ of abortion and more than $20 \%$ of obstetric-related maternal mortality can be prevented. ${ }^{4}$ Ahmed et al (2012) reported that the number of maternal deaths would have been 1.8 times higher than the 2008 total without the use of contraceptive. ${ }^{5}$
Knowledge, attitude and perception of contraception will cause impacts to the community. Biney observed that women who had no knowledge on contraception will cause to failure of contraceptive use. ${ }^{6}$ This will in turn lead to increase incidence of unintended pregnancies which followed by induced unsafe abortions. Rasch et al ( 2007) concluded that women who lack of contraceptive knowledge will choose abortion as the choice for termination of pregnancy. ${ }^{7}$ The lack of training and inadequate in number of healthcare providers may cause barriers for women to access to contraception. ${ }^{8}$ In order to increase the quality of contraceptive services, health care providers should equip themselves with adequate knowledge and training in counselling skills so that reliable information can be given when they counsel their patients. This will help in reducing the number of unintended pregnancy and unsafe abortion globally. ${ }^{8}$ Considering the future role of medical students as family planning counsellors as well as 
educator, their understanding and perception on contraceptive use and counselling should be acquired adequately and updated even during undergraduate training. The knowledge of contraception within medical students in Universiti Putra Malaysia had never been examined before. Therefore, it is imperative to know their understanding towards contraception so that adequate trainings can be given to undergraduate medical students before they graduate and serve our community. Thus, this study is carried out to assess the level of knowledge and attitude of contraception among medical students in Universiti Putra Malaysia and their perception of education and training in sexual and reproductive health and contraception practice as well as the association between sociodemographic factors and socio-economic factors with the level of knowledge and attitude on contraception.

\section{METHODOLOGY}

\section{Study Design and sampling}

A cross-sectional survey was conducted using selfreported questionnaire among medical students in Universiti Putra Malaysia. A total of 278 students responded to the questionnaires. Students who were in their clinical training chosen to participate as our sampling population in this study because they had gone through clinical postings and have basic clinical knowledge regarding family planning and contraception.

The sampling method that was used in this study was simple random sampling. The list of third year, fourth year and fifth year medical students was obtained. The respondents were chosen by using random number table. The questionnaires on knowledge, attitude and perception on contraception were distributed to the third year, fourth year and fifth year medical students who had been chosen through simple random sampling method.

The formula from (Lachenbrunch, Lwanga \& Lemeshow, 1991) was used to calculate the sample size: For main objective (To determine the knowledge, attitude and perception of contraception among undergraduate medical students in Universiti Putra Malaysia (UPM). We employed larger sample size to determine the outcomes of this study and over all sample size for this study will be 278 for all objectives. The power of the study is Power of the study is $80 \%$. Students with inclusion criteria will be approached by researcher and co- researchers during recession time or after office hour and through explanation will be given before obtaining consent for participation in this study. The information booklet was given to the respondents before answer the survey questions and permission to participation was obtained with written consent. Inclusion criteria are both genders of third year, fourth year and fifth year medical students and exclusion criteria include undergraduate medical students who in their pre-clinical year. (first and second year) and house officers.

\section{Instrument}

The questionnaire survey contained four sections. Section A included socio-demographic characteristics such as ethnicity, gender, place of birth, and marital status. Section B included questions related to knowledge towards contraception. Section C consisted of 14 questions regarding attitude towards contraception. Lastly, section $D$ consisted on questions regarding the perception of education and training in sexual and reproductive health among medical students. Validated five-point Likert scale (no response/ disagree/ strongly disagree/ agree/ strongly agree) were used to determine the student's knowledge, attitude, perception towards contraception and family planning. The data was collected using self-administered questionnaire.

The questionnaire consists of 4 sections. Section A of Socio-demographic of the medical students include age, gender, place of birth, race, marital status, socio-economy (father and mother educational status), number of siblings. Section B of Knowledge towards contraception include contraceptive pills, emergency contraception, condom. knowledge of contraception was assessed based on 6 questions. Each question had 5 answers which were "Strongly disagree", "Disagree", Neutral "Agree" and "Strongly agree". Reverse scoring was used to calculate the marks for negatively worded questions. Total score more than 16 is considered as good and less than 16 is considered as bad knowledge towards contraception. Section C of attitude towards contraception, total score more than 38 is considered as positive towards and less than 38 is negative towards contraception. Section D of Perception of education and training in sexual and reproductive health among medical students include coverage of topic of reproductive health in curriculum, access of theoretical knowledge of sexual and reproductive health, clinical practice during practice, source of information, confidence in counselling patient, perception on current health care provider.

The components of the questionnaire were based on the validated questions from previous research that was carried out by a group of researchers from University of New Hampshire. The questionnaires were further modified to ensure the acceptability and feasibility of the questionnaires to the respondents. Besides, pretest validity (content validity) as well as reliability analysis was conducted in the Faculty of Medicine and Health Science, UPM (Academic staffs from Statistical and community medicine). The aim was to ensure the validity and reliability of the questionnaire. For answering the questionnaire, adequate time (45 minutes) was allocated for each respondent to answer the questionnaire and 
given with sealed envelope to maintain confidentiality and anonymity.

\section{Data analysis}

Information collected from the questionnaires was filled into master sheet using the Statistical Package for Social Science (SPSS) version 22. After data entry, data transformation and data analysis were carried out. Chi-square and Fisher's Exact test were used to compare the data. Descriptive characteristic such as mean, median, frequency and percentage were calculated. All tests were two sided and the result was considered as significant if $\mathrm{P}<0.05$.

\section{Definitions}

Attitude is the way that people think and feel about something especially when this shows in the way they behave.

Knowledge: The fact or condition of knowing something with familiarity gained through experience

Perception: a belief or opinion, often held by many people and based on how things seem, Contraception: (birth control) prevents pregnan cy by interfering with the normal process of ovul ation, fertilization, andimplantation.

Family planning: allows individuals and couples to anticipate and attain their desired number of children and the spacing and timing of their births. It is achieved through use of contraceptive methods and the treatment of involuntary infertility.

\section{Ethical consideration}

The approval from Ethic Committee for Research Involving Human Subject (Jawatankuasa Etika Universiti Melibatkan Manusia, JKEUPM) was obtained. The information of respondents that was obtained through the questionnaires was kept confidential and anonymous. Written consent for the participation of the respondents was obtained before participation in this study. The approval to conduct research in Faculty of Medicine and Health Sciences was obtained before the research was carried out.

\section{RESULT}

A total of 278 medical students from third year, fourth year and final year were participated in the study (response rate 100\%). The association between socio-demographic and socio-economic factors with the level of knowledge and attitude among respondents is shown in Table 1. Gender, ethnicity, place of birth, marital status, and father educational level were significantly associated with the level of knowledge $(p<0 \cdot 05)$. There was a higher proportion of male $(53.4 \%)$ who had good knowledge on contraception as compared to female $(39.5 \%)$ though female participants are more than male participants. For ethnicity, considering only the three main races in Malaysia, Chinese $(54 \cdot 3 \%)$ had a higher percentage of having good knowledge as compare to Malay (38.5\%) and Indian (42.1\%). Besides, there was a higher percentage of rural group respondents $(55 \cdot 8 \%)$ and those who were married $(100 \%)$ in getting good level of knowledge as compared to their counterpart. However, interestingly those respondents who father had primary education level $(70 \cdot 6 \%)$ showed a higher percentage in having good level of knowledge. It indicates that regardless of parents' educational level and place of birth, medical students have own initiation and enthusiasm to achieve sufficient knowledge regards to their program.

There was significant association between place of birth, ethnicity, and marital status with level of attitude. According to the result, there were a higher percentage of married $(100.0 \%)$ and urban group (51.6\%) respondents who had positive attitude as compared to their counterpart (37.2\%). Besides, Indian (63.3\%) had the highest percentage $(80 \%)$ of having good attitude among the main races in Malaysia. Figure 1 shows the level of knowledge and attitude among the respondents. Most of the students had poor level of knowledge $(56 \cdot 1 \%)$ and negative attitude towards contraception (59.2\%).

Table 2 shows the perception of education in sexual and reproductive health and training in practice of contraception among medical students. Most of the students thought that sexual and reproductive health $(48.9 \%)$ and contraceptive methods $(62.2 \%)$ had been included and taught sufficiently in their curriculum. However, most of them realized that family planning service was not included during their clinical practice $(50.4 \%)$. Besides, most of the students considered that they had fair knowledge of sexual and reproductive health (45.3\%). Figure 1 shows the level of knowledge and attitude among the respondents. Most of the students had poor level of knowledge $(56 \cdot 1 \%)$ and negative attitude towards contraception (59.2\%). 
Table 1: Relationship between socio-demographic and socio-economic factors with level of knowledge and attitude

\begin{tabular}{|c|c|c|c|c|c|c|}
\hline \multirow[t]{2}{*}{ Variables } & \multicolumn{2}{|c|}{ Level of Knowledge, $n$ (\%) } & \multirow{2}{*}{$\begin{array}{l}\text { Test of } \\
\text { significant }\end{array}$} & \multicolumn{2}{|c|}{ Level of Attitude, n (\%) } & \multirow{2}{*}{$\begin{array}{l}\text { Test of } \\
\text { significant }\end{array}$} \\
\hline & Poor & Good & & Negative & Positive & \\
\hline \multicolumn{7}{|l|}{ Gender } \\
\hline Female & $115(60 \cdot 5)$ & $75(39 \cdot 5)$ & $x^{2}=4 \cdot 743$ & $94(49 \cdot 5)$ & $96(50 \cdot 5)$ & $x^{2}=2 \cdot 791$ \\
\hline Male & $41(46 \cdot 6)$ & $47(53 \cdot 4)$ & $p=0.029^{*}$ & $53(60 \cdot 2)$ & $35(39 \cdot 8)$ & $p=0.095$ \\
\hline \multicolumn{7}{|c|}{ Place of birth } \\
\hline Rural & $38(44 \cdot 2)$ & $48(55 \cdot 8)$ & $x^{2}=7 \cdot 195$ & $54(62 \cdot 9)$ & $32(37 \cdot 2)$ & $x^{2}=4 \cdot 911$ \\
\hline Urban & $118(61 \cdot 5)$ & $74(38 \cdot 5)$ & $p=0 \cdot 007^{*}$ & $93(48 \cdot 4)$ & $99(51 \cdot 6)$ & $p=0 \cdot 027^{*}$ \\
\hline \multicolumn{7}{|l|}{ Ethnicity } \\
\hline Malay & $110(61 \cdot 5)$ & $69(38 \cdot 5)$ & $x^{2}=7 \cdot 940$ & $108(60 \cdot 3)$ & $71(39 \cdot 7)$ & $x^{2}=13 \cdot 115$ \\
\hline Chinese & $32(45 \cdot 7)$ & $38(54 \cdot 3)$ & $p=0 \cdot 047^{*}$ & $30(42 \cdot 9)$ & $40(57 \cdot 1)$ & $p=0.004^{*}$ \\
\hline Indian & $11(57 \cdot 9)$ & $8(42 \cdot 1)$ & & $7(36 \cdot 8)$ & $12(63 \cdot 3)$ & \\
\hline Others & $3(30 \cdot 0)$ & $7(70 \cdot 0)$ & & $2(20 \cdot 0)$ & $8(80 \cdot 0)$ & \\
\hline \multicolumn{7}{|c|}{ Marital status } \\
\hline Single & $156(56 \cdot 9)$ & $118(43 \cdot 1)$ & $\mathrm{p}=0.036^{*}$ & $147(53 \cdot 6)$ & $127(46 \cdot 6)$ & $p=0.048^{*}$ \\
\hline Married & $0(0.0)$ & $4(100 \cdot 0)$ & & $0(0.0)$ & $4(100 \cdot 0)$ & \\
\hline \multicolumn{7}{|c|}{$\begin{array}{l}\text { Father } \\
\text { Educational } \\
\text { Status }\end{array}$} \\
\hline Primary & $93(29 \cdot 4)$ & $12(70 \cdot 6)$ & $x^{2}=10 \cdot 759$ & $10(58 \cdot 8)$ & $7(41 \cdot 2)$ & $x^{2}=0 \cdot 736$ \\
\hline Secondary & $58(68 \cdot 2)$ & $27(13 \cdot 8)$ & $p=0.005^{*}$ & $42(49.4)$ & $43(50 \cdot 6)$ & $p=0.692$ \\
\hline Tertiary & $93(52 \cdot 8)$ & $83(47 \cdot 2)$ & & $95(54 \cdot 0)$ & $81(46 \cdot 0)$ & \\
\hline \multicolumn{7}{|c|}{$\begin{array}{l}\text { Mother } \\
\text { Educational } \\
\text { Status }\end{array}$} \\
\hline Primary & $14(48 \cdot 3)$ & $15(51 \cdot 7)$ & $x^{2}=0.813$ & $18(62 \cdot 1)$ & $11(37 \cdot 9)$ & $x^{2}=1 \cdot 691$ \\
\hline Secondary & $63(57 \cdot 3)$ & $47(42 \cdot 7)$ & $p=0.666$ & $60(54 \cdot 5)$ & $50(45 \cdot 5)$ & $p=0.429$ \\
\hline Tertiary & $79(56 \cdot 8)$ & $60(43 \cdot 2)$ & & $69(49.6)$ & $70(50 \cdot 4)$ & \\
\hline
\end{tabular}

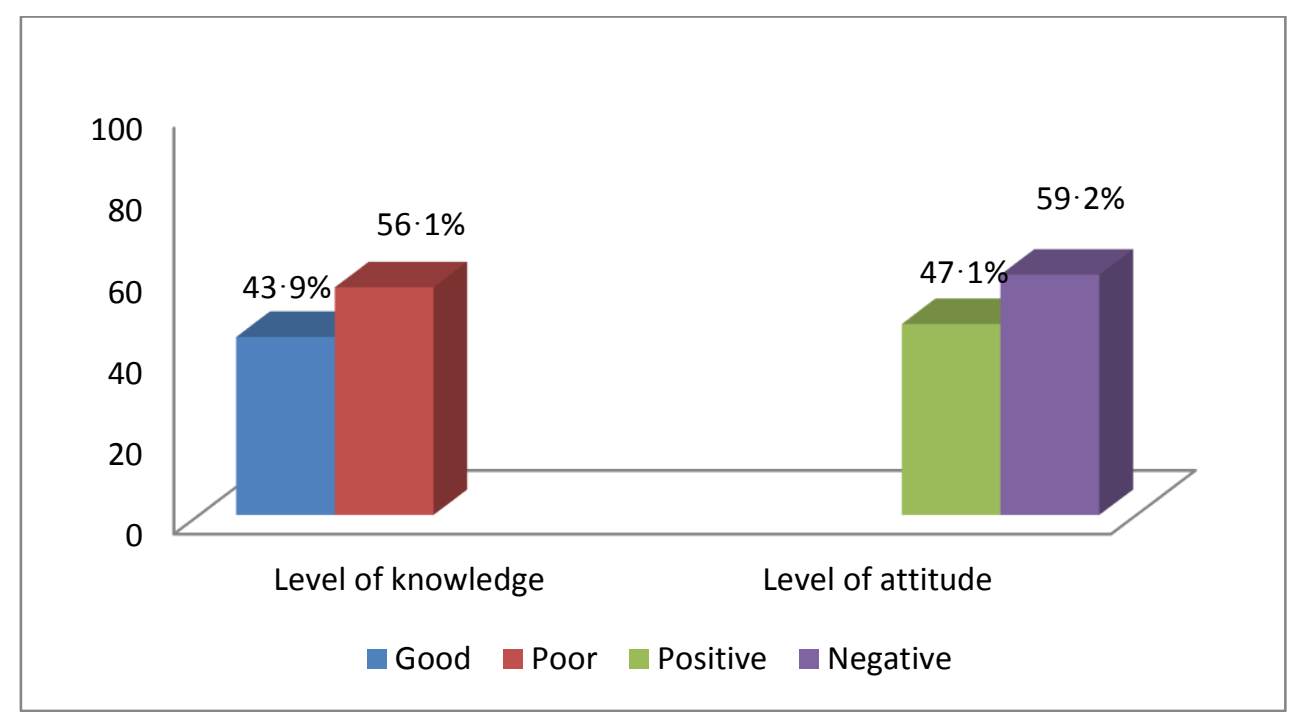

Figure 1: Level of knowledge and attitude among respondents 
Regarding the sources of information of contraception and family planning, most of the students obtained the information through formal lectures and tutorial (32.1\%) rather than via media, public forum as well as workshop or seminar. About $64 \%$ of students considered that they had adequate information regarding contraceptive usage and family planning counselling during clinical training. However, majority of the students realized that they did not have training in counselling the patients for family planning during clinical posting (57.6\%) and they did not have enough confidence to counsel the patient for appropriate family planning method (62.2\%). In addition, $93.9 \%$ of undergraduate medical students felt that sexual education in their curriculum was beneficial. Lastly, most of the students perceived that health care providers had adequately trained to give sufficient information regarding contraception and family planning (78.1\%).

All of the data with $p$ value less than 0.25 was chosen to be analysed in logistic regression in Table 3. There were a few variables that were significant in relation to level of knowledge. The variable of place of birth, which was rural group, was statistically significant. For rural group, the odds of getting good knowledge were 2.422 times more than the odds of the urban counterpart in getting good knowledge. Moreover, the variable of father educational status was statistically significant. The odds of getting good knowledge for those who father had secondary education level were 0.417 times that the odds of those fathers with tertiary education level in getting good level of knowledge. This finding is contradicted to the study done by Tunau et al (2016) stated that better knowledge of family planning and practice of contraception among urban area than rural area though need for intensification of sexual health education across the population. ${ }^{9}$

As for the level of attitude, the variable for gender was statistically significant which is shown in Table 4. The odds of getting positive attitude for female were $2 \cdot 167$ times more than the odds of male in getting positive level of attitude. Besides, the variable of ethnicity, which was Malay, was statistically significant. For Malay, the odds of getting positive attitude were 0.143 times that the odds of the minor ethnics (others) in having positive attitude.

As for the level of attitude, the variable for gender was statistically significant which is shown in Table 4. The odds of getting positive attitude for female were $2 \cdot 167$ times more than the odds of male in getting positive level of attitude. Besides, the variable of ethnicity, which was Malay, was statistically significant. For Malay, the odds of getting positive attitude were 0.143 times that the odds of the minor ethnics (others) in having positive attitude.

\section{DISCUSSION}

This study was conducted to assess the knowledge, attitude and perception of contraception among medical students at Universiti Putra Malaysia. Our finding suggested that most of the students had inadequate knowledge and negative attitude towards contraception and family planning. In concordance with other studies, our study identified that the majority of female staff at Universiti Putra Malaysia, had poor or inadequate level of knowledge on contraception and family planning.. ${ }^{10}$ The result for level of attitude was negative compared to a study in Maharashtra, India which revealed that the attitudes towards contraception among fifth year medical students in 27 medical colleges in Maharashtra were mainly positive. ${ }^{11}$ However, this might be linked to the religious values and cultural norms differences revolving issues on sexuality in Malaysia. ${ }^{12}$

Most of the respondents believed that sexual reproductive health and contraceptive methods had been taught sufficiently in their curriculum. However, most of them realized that they did not have enough clinical practice and training in family planning service during their clinical posting. This can explain why most of the respondents felt that they had only fair knowledge on contraception but lack of clinical experience and confidence to counsel the patient for appropriate family planning method in clinical practice. In the other hand, most of the respondents thought that sexual education in curriculum is beneficial. According to a research was carried out on Sexual Health Selective (SHS) among medical students in United State, it was reported that there was an increase in openmindedness level of knowledge about sexual health issues compared with baseline immediately after the SHS and 3 months later. ${ }^{13}$ Lastly, majority of them perceived that health care providers or educators in Malaysia had adequately trained to give sufficient information regarding contraception and family planning.

There was significant association between gender, place of birth, ethnicity, marital status, and father educational status with level of knowledge. The result for ethnicity was similar to other study which also showed that Chinese had a higher knowledge level on contraception. ${ }^{14}$ The result can be intricately related to the cultural belief and sensitivity surrounding sexual issues. For gender, the result was shown that more male correspondents had good knowledge which in contrast with previous research which showed that more female had good to average knowledge on contraception. ${ }^{14}$ The difference between both of the findings can be related to the differences in the perception on family planning between male and female. ${ }^{15}$ The percentage of respondents who were having positive perceptive towards contraceptive practice was higher in female as compared to male while percentage of 
respondents who were having negative perceptive towards contraceptive practice was higher in male than female. It. may be due to larger female correspondents than male counterparts with different cultural believe for family planning, lack of knowledge and conservative society.

Table 2: Distribution of Perception on Contraception among Respondents

\begin{tabular}{ll}
\hline Variables & Respondents $(n=278)$
\end{tabular}

n $\quad$ Total (\%)

Was sexual and reproductive health included in your curriculum?

Not at all

Somewhat but minimal $\quad 10$

Sufficiently

Have contraceptive methods been taught in your program?

Not at all

Somewhat but minimal

Sufficiently

How do you assess your theoretical knowledge of sexual and reproductive health and practice of contraception?

$\begin{array}{lll}\text { Poor } & 10 & 3.6 \\ \text { Fair } & 126 & 45.3 \\ \text { Good } & 112 & 40.3 \\ \text { Very good } & 30 & 10.8\end{array}$

Do you have clinical practice in family planning service during your training? ( Contraception practice)

Yes

No

How do you get the source of information regarding contraception and family planning?

Formal lectures and tutorials

Media

Newspaper

Magazine

Internet

Health facilities (Health clinic or family planning

clinic)

Workshop and seminar

12.6

Do you have adequate information regarding contraceptive usage and family planning counseling during your clinical training?

Do you have enough confidence to counsel the patient for appropriate family planning method (Contraception) ?

Yes

No

Do you think sexual education in your curriculum is beneficial?

Yes

No

93.9

Do you think health care provider or educator have adequately trained to give sufficient information regarding contraception and family planning? 
Table 3: Logistic regression between significant factors $(p<0 \cdot 25)$ (gender, place of birth, ethnicity, marital status and father educational level) in relation to good level of knowledge

\begin{tabular}{|c|c|c|c|c|}
\hline \multirow[t]{2}{*}{ Variables } & \multirow[t]{2}{*}{ P-value } & \multirow[t]{2}{*}{$\operatorname{Exp}(B)$} & \multicolumn{2}{|c|}{ 95\% Cl for $\operatorname{Exp}(B)$} \\
\hline & & & Lower & Upper \\
\hline \multicolumn{5}{|l|}{ Gender } \\
\hline Female & $0 \cdot 257$ & 0.722 & $0 \cdot 412$ & $1 \cdot 267$ \\
\hline Male & \multicolumn{4}{|c|}{ Reference group } \\
\hline \multicolumn{5}{|c|}{ Place of birth } \\
\hline Rural & $0 \cdot 002^{*}$ & $2 \cdot 422$ & $1 \cdot 385$ & $4 \cdot 235$ \\
\hline Urban & \multicolumn{4}{|c|}{ Reference group } \\
\hline \multicolumn{5}{|l|}{ Ethnicity } \\
\hline Malay & $0 \cdot 112$ & $0 \cdot 292$ & 0.064 & $1 \cdot 331$ \\
\hline Chinese & $0 \cdot 581$ & 0.645 & $0 \cdot 136$ & $3 \cdot 067$ \\
\hline Indian & 0.543 & $0 \cdot 578$ & 0.099 & $3 \cdot 375$ \\
\hline Others & \multicolumn{4}{|c|}{ Reference group } \\
\hline \multicolumn{5}{|c|}{ Marital status } \\
\hline Single & 0.999 & 0.000 & 0.000 & \\
\hline Married & \multicolumn{4}{|c|}{ Reference group } \\
\hline \multicolumn{5}{|c|}{ Father educational status } \\
\hline Primary & $0 \cdot 115$ & $2 \cdot 515$ & 0.798 & $7 \cdot 933$ \\
\hline Secondary & $0.004^{*}$ & $0 \cdot 417$ & $0 \cdot 230$ & 0.756 \\
\hline Tertiary & \multicolumn{4}{|c|}{ Reference group } \\
\hline
\end{tabular}

Table 4: Logistic regression between significant factors $(p<0 \cdot 25)$ (place of birth, ethnicity and marital status) in relation to positive level of attitude

\begin{tabular}{|c|c|c|c|c|}
\hline \multirow[t]{2}{*}{ Variables } & \multirow[t]{2}{*}{ P-value } & \multirow[t]{2}{*}{$\operatorname{Exp}(B)$} & \multicolumn{2}{|c|}{$95 \% \mathrm{Cl}$ for $\operatorname{Exp}(B)$} \\
\hline & & & Lower & Upper \\
\hline \multicolumn{5}{|l|}{ Gender } \\
\hline Female & $0.008^{*}$ & $2 \cdot 167$ & $1 \cdot 219$ & $3 \cdot 853$ \\
\hline Male & \multicolumn{4}{|c|}{ Reference group } \\
\hline \multicolumn{5}{|c|}{ Place of birth } \\
\hline Rural & 0.063 & $0 \cdot 594$ & $0 \cdot 344$ & $1 \cdot 028$ \\
\hline Urban & \multicolumn{4}{|c|}{ Reference group } \\
\hline \multicolumn{5}{|l|}{ Ethnicity } \\
\hline Malay & $0.020^{*}$ & $0 \cdot 143$ & 0.028 & 0.736 \\
\hline Chinese & $0 \cdot 242$ & $0 \cdot 369$ & 0.070 & 1.958 \\
\hline Indian & 0.326 & 0.393 & 0.061 & 2.534 \\
\hline Others & \multicolumn{4}{|c|}{ Reference group } \\
\hline \multicolumn{5}{|c|}{ Marital Status } \\
\hline Single & 0.999 & 0.000 & 0.000 & \\
\hline Married & \multicolumn{4}{|c|}{ Reference group } \\
\hline
\end{tabular}

As for marital status, the result was in concordance with the research that was carried out among senior pharmacy students in Malaysia which also showed a significant relationship between marital status and level of knowledge. ${ }^{16}$ There was a higher percentage of those who were married in getting good knowledge on contraception. The possible explanation is that respondents who are married more likely to be sexually active. Thus, they tend to have more exploring knowledge of family planning and exposure on contraceptive methods compare to those who are still single.

In addition, there was significant association between place of birth, ethnicity, and marital status with level of attitude. The possible explanation for low level of knowledge among those who are single is that they do not exposed to any kind of relationship since they are still single with no sexual exposure as well as obligation to enquire regarding contraception and family planning. that may lead to poor attitudes 
towards contraception with inadequate basic principle of knowledge on contraception and family planning.

As for ethnicity, Indian had the highest percentage of respondents having positive attitude towards contraception, followed by Chinese and Malay. It was contradicted with a study in a public university in Malaysia. The attitude score was highest among the Malays (median=38.0) and lowest among the Chinese (median=31.0), with the Indians and natives of Sabah or Sarawak occupying an intermediate position (median=34.0). It can be explained that east coast of Malaysia, ethnic Malay population are significantly more than Chinese and Indian ethnic group.

Overall, we found that both the knowledge and awareness of contraceptives among medical students at UPM are low with some degree of misperceptions. we have confidence and expectation that this study will contribute to focusing on providing reproductive health education and counselling as well as demonstrating the importance of collaboration and communication among medical professional, public and media resources to disseminate factual information, regarding contraception. ${ }^{17}$

\section{CONCLUSION}

From this study, we found that there were a higher percentage of respondents who had poor knowledge and negative attitude towards contraception. The increasing trend of premarital sexual experience and unintended pregnancies in Malaysia warrants sustained and serious attention. The sensitivities of sex-related issues in a multi racial country create various types of barriers to sexual and reproductive health information, support and practices.

Improving knowledge and attitude of medical students on contraception with collaborated public health education leads to reduction of unintended pregnancies and consequences of child dumping and abrupt disruption of academic career among unmarried young adolescents with adequate family planning. This study therefore recommends that information regarding contraception and family planning should be vehemently promoted as considering the future role of medical students as family planning educator as well as counsellors. It is not only important to determine their knowledge, attitude and perception towards contraception but also should be updated for improvement on the quality of future healthcare which may lead to further reduction in maternal morbidity mortality and improving maternal and child health.

\section{LIMITATIONS}

There are certain limitations in our study which might affect our outcomes of the result. One of the limitations of our study is the limited time frame to collect the data which only four weeks before submitting the final report. During that period, both final year and year four undergraduate medical students were having examination and not keen on participation in this study and many rejections received as expected. In addition, as this was a self-report behavioural questionnaire survey, social desirability bias might occur. Having sexual relationship before marriage is culturally intolerable in Malaysia, it is not possible to determine whether the respondents tended to avoid answering some sensitive questions by choosing the answers that they believe are more socially desirable or acceptable. Lastly, out of the 278 respondents that participated in this study, there was unequal distribution of genders, ethnic groups and it was unclear if the fact unequal distribution of sociodemographic factors of the respondents had any influence over the results from this study.

\section{ACKNOWLEDGEMENT}

The authors appreciate the Dean and the Deputy Dean (Academic) of the Faculty of Medicine and Health Sciences, Universiti Putra Malaysia and Ethic Committee for Research Involving Human Subjects (JKEUPM) for giving the permission to conduct this study. Last but not least, we thank all the respondents who participated in this study.

Conflict of interest: Authors declare no conflict of interest.

\section{REFERENCES}

1 G WHO. Family planning /contraception 2017. Retrieved from: http: / /www. who.int/mediacentre/facts heets/fs351/ en/ (assessed 20 July 2017)

2 Haddad, L., \& Nour, N. (2009). Unsafe Abortion: Unnecessary Maternal Mortality. Retrieved from http://dx.doi.org/PMC2709326 (assessed 12 April 2016)

3 Statistics: RRAAM: Reproductive Rights Advocacy Alliance Malaysia 2016. Rraam.org. Retrieved 6 April 2016, from

http: / /www.rraam.org/resources/statist ics/. (assessed 6 April 2016)

4 Hogmark, S., Klingberg-Allvin, M., Gemzell-Danielsson, K., Ohlsson, H., \& Essen, B. Medical students' knowledge, attitudes and perceptions towards contraceptive use and counselling: a cross-sectional survey in Maharashtra, India. BMJ Open 2013; 3: e003739e003739.

5 Ahmed, S., Li, Q., Liu, L., \& Tsui, A. Maternal deaths averted by contraceptive 
use: an analysis of 172 countries. Lancet 2012; 380: 111-125.

Biney, A.A.E. Exploring Contraceptive Knowledge and Use among Women Experiencing Induced Abortion in the Greater Accra Region, Ghana. African Journal of Reproductive Health 2011; 15: 37-46.

7 Rasch, V., Knudsen, L., Gammeltoft, T., Christensen, J., Erenbjerg, M., Christensen, J., \& Sorensen, J. (2007). Contraceptive attitudes and contraceptive failure among women requesting induced abortion in Denmark. Human Reproduction 2007; 22: 1320-1326.

8 Eniojukan Joshua, F. (2016). Knowledge, Perception and Practice of Contraception among Staff and Students in a University Community in Delta State, Nigeria. UK JournalOfPharmaceuticalBiosciences, 4(1) .http://dx.doi.org/10.20510/ukjpb/4/i1 187848 .

Tunau, K., Awosan, K., Adamu, H., Muhammad, U., Hassan, M., \& Nasir, S. et al. (2016). Comparative assessment of modern contraceptives' knowledge and utilization among women in urban and rural communities of Sokoto State, Nigeria. Journal of Medicine and Medical Sciences; 7(1): 006-014.

Johnson, K., Rullo, J., \& Faubion, S. (2015). Student-Initiated Sexual Health Selective as a Curricular Tool. Sexual Medicine, 3(2), 118-127. http://dx.doi.org/10.1002/sm2.57.

Hogmark S, Klingberg-Allvin M, GemzellDanielsson K, Ohlsson H, Essén B. Medical students' knowledge, attitudes and perceptions towards contraceptive use and counselling: a cross-sectional survey in Maharashtra, India. BMJ Open 2013; 3: e003739.
12 Najafi F, Abdul Rahman H, Hanafiah Juni M. Barriers to Modern Contraceptive Practices among Selected Married Women in a Public University in Malaysia. GJHS 2011; 3. DOI:10.5539/gjhs. v3n2p50.

13 Johnson K, Rullo J, Faubion S. StudentInitiated Sexual Health Selective as a Curricular Tool. Sexual Medicine 2015; 3: 118-127.

14 Wong L. An exploration of knowledge, attitudes and behaviours of young multiethnic Muslim-majority society in Malaysia in relation to reproductive and premarital sexual practices. BMC Public Health 2012; 12. DOI:10.1186/1471-245812-865.

15 Henry Nsubuga ${ }^{*} \dagger$, Juliet N. Sekandi2,3†, Hassard Sempeera2 and Fredrick E. Makumbi2 Contraceptive use, knowledge, attitude, perceptions and sexual behavior among female University students in Uganda: a cross-sectional survey. BMC Women's Health (2016) : 2-11. DOI 10.1186/s12905-016-0286-6

16 Ahmad A, Awad A, Elkalmi $\mathrm{R}$ et al. Knowledge, awareness, and perception of contraception among senior pharmacy students in Malaysia: A pilot study. Journal of Research in Pharmacy Practice 2015; 4: 94.

17 Nhi Ngoc Yen Tran, Trung Quang Vo. Knowledge, Perceptions and attitudes toward contraceptive medicine among undergraduate students in Southern Vietnam. Asian Journal of Pharmaceutics • Jan-March 2018 (Special Issue) | 590-98. 